\title{
Maternal and perinatal outcome of acute pancreatitis during pregnancy: a 5 year experience at a tertiary care centre
}

\author{
Vishnu Priya KMN*, Sheela CN, Shruti Banka, Mahalakshmi T.
}

Department of Obstetrics and Gynaecology, St. John's Medical College Hospital, Bangalore, Karnataka, India

Received: 15 September 2016

Revised: 19 September 2016

Accepted: 08 October 2016

\section{* Correspondence:}

Dr. Vishnu Priya KMN,

E-mail: kmn_priyanil@yahoo.co.in

Copyright: () the author(s), publisher and licensee Medip Academy. This is an open-access article distributed under the terms of the Creative Commons Attribution Non-Commercial License, which permits unrestricted non-commercial use, distribution, and reproduction in any medium, provided the original work is properly cited.

\section{ABSTRACT}

Background: Acute pancreatitis in pregnancy (APIP) is rare and occurs in approximately 1 in 1000 to 1 in 4000 births. The most common symptom of acute pancreatitis is epigastric pain radiating to the back which is accompanied by nausea, vomiting and fever. The aim of the study was to evaluate the maternal and perinatal outcome of acute pancreatitis during pregnancy.

Methods: Six antenatal mothers identified with acute pancreatitis at St. John's Medical College Hospital, Bengaluru from June 2011 to March 2016 were followed up in the antenatal, postnatal period and their outcomes were evaluated. Results: There were six cases of acute pancreatitis, with 11,053 deliveries during this 5 year study. Incidence was 1 in 1831. All patients presented with epigastric pain, vomiting and required repeated episodes of admission. There were 14 episodes of acute pancreatitis in these 6 patients. Pancreatitis was severe in 3 patients, with most attacks occurring in third trimester. Etiology was biliary pancreatitis (gallstones) in 2 patients, preeclampsia in 2, idiopathic 1 and hypertriglyceridemia in one patient. Five patients delivered preterm. There were no abortions, fetal loss, maternal and neonatal mortality.

Conclusions: The course of acute pancreatitis in pregnancy is usually mild and self-limiting. But, it can be rapidly progressive and fulminant with complications like electrolyte imbalance, ARDS and DIC. Most patients delivered preterm. Conservative management till delivery by multidisciplinary team lead to good maternal and perinatal outcome.

Keywords: APIP, ARDS, ERCP

\section{INTRODUCTION}

Acute pancreatitis in pregnancy (APIP) is rare and occurs in approximately 1 in 1000 to 1 in 4000 births. $^{1}$ The most common symptom of acute pancreatitis is epigastric pain radiating to the back which is accompanied by nausea, vomiting and fever. ${ }^{2}$ It is associated with gallstones in 40$66 \%$, hypertriglyceridemia in 5-56\%, and rarely preeclampsia. ${ }^{3,4}$ Preeclampsia causes acute pancreatitis due to the microvascular abnormalities involving splanchnic circulation which results in pancreatic ischemic changes. ${ }^{5-7}$
Physiological hypertriglyceridemia in pregnancy rarely exceeds $300 \mathrm{mg} / \mathrm{dL}$; the levels of triglycerides that cause acute pancreatitis should be $>1000 \mathrm{mg} / \mathrm{dL}$, seen in women with pre-existing disorders of lipid metabolism. ${ }^{8}$ The other causes are alcoholism, fatty liver of pregnancy, trauma and idiopathic. Hypercalcemia due to hyperparathyroidism leads to acute pancreatitis. Calcium deposition in the pancreatic duct and activation of trypsinogen within the parenchyma are possible explanations. ${ }^{9}$

The course of pancreatitis during pregnancy is usually mild and self-limiting, but can be rapidly progressive and fulminant due to complications such as pancreatic 
necrosis, acute respiratory distress syndrome (ARDS), disseminated intravascular coagulopathy (DIC) and multi-organ failure. ${ }^{2}$

\section{METHODS}

In this observational study conducted at St. John's Medical College and Hospital, Bengaluru between June 2011 - March 2016, pregnant women diagnosed with acute pancreatitis were observed for antenatal, postnatal complications and neonatal outcome. All six cases were treated by multi-disciplinary team including Obstetrician, Gastroenterologist, Surgeon and Intensivist. Data on maternal age, obstetric history, gestational age at onset and delivery, etiology of pancreatitis, management, complications, and the length of hospital stay, maternal and perinatal outcome was collected.

The diagnosis of acute pancreatitis was determined based on the clinical history and examination, ultrasound and necessary laboratory investigations and management was planned accordingly.

Antenatal mothers presenting with clinical features suggestive of acute pancreatitis were evaluated by a protocol which included complete blood count, serum amylase, serum lipase, serum calcium, lipid profile, liver function test, renal function test, serum electrolytes and ultrasound. Etiology in each case was determined and the management was tailored to each patient.

Biliary pancreatitis was diagnosed when gallstones or sludge were identified in the biliary tree or the gallbladder. Hyperlipidemic pancreatitis was diagnosed when the serum triglyceride level was $>1000 \mathrm{mg} / \mathrm{dL}$ (baseline normal value $<150 \mathrm{mg} / \mathrm{dL}$ ). Pancreatitis due to hypercalcemia was diagnosed when the serum total calcium level was $>10.5 \mathrm{mg} / \mathrm{dL}$. Pancreatitis secondary to preeclampsia with or without HELLP syndrome was a diagnosis by exclusion; in the absence of other causes for pancreatitis. Cases were classified as idiopathic when an etiologic factor could not be determined.

Severity of acute pancreatitis was evaluated using Ranson's criteria. ${ }^{10}$ Ranson's criteria includes age $>55$ years, white blood cell count $>16000$ cells $/ \mathrm{mm}^{3}$, blood glucose $>10 \mathrm{mmol} / \mathrm{L}(>200 \mathrm{mg} / \mathrm{dL})$, serum AST >250 $\mathrm{IU} / \mathrm{L}$, serum $\mathrm{LDH}>350 \mathrm{IU} / \mathrm{L}$ at admission and serum calcium $<2 \mathrm{mmol} / \mathrm{L}(>8 \mathrm{mg} / \mathrm{dL})$, haematocrit fall $>10 \%$, pO2 $<60 \mathrm{mmHg}$, BUN increased by $\mathrm{mmol} / \mathrm{L}(\geq 5 \mathrm{mg} / \mathrm{dL})$ after IV fluid hydration, base deficit $>4 \mathrm{mEq} / \mathrm{L}$, sequestration of fluids $>6 \mathrm{~L}$ at 48 th hour of admission. ${ }^{6}$ Acute pancreatitis was defined as mild when $\leq 2$ criteria were present and severe when $\geq 3$ criteria were present.

Management protocol was mainly supportive with anticipation of complications, so that pregnancy could be continued and definitive management accomplished in postpartum period. Patients were managed with analgesics, antipyretics, antiemetics, proton pump inhibitors and adequate hydration. Fetus was monitored by nonstress test, biophysical profile and obstetric ultrasound; and antenatal corticosteroids given when indicated.

RESULTS

Table 1: Demographic and clinical features of patients with acute pancreatitis in pregnancy.

\begin{tabular}{|c|c|c|c|c|c|c|}
\hline $\begin{array}{l}\text { Age } \\
(y)\end{array}$ & O.S & GAO & GAD & Etiology & $\begin{array}{l}\text { Severity (Ranson's } \\
\text { score) }\end{array}$ & Complications \\
\hline 27 & G2A1 & $31+6$ & $33+2$ & Gallstone & 2 (mild) & $\begin{array}{l}\text { Electrolyte imbalance, } \\
\text { ARDS }\end{array}$ \\
\hline 26 & G4A3 & $30+1$ & $30+2$ & Preeclampsia & 5 (severe) & ARDS \\
\hline 20 & G1 & $37+4$ & 38 & Gallstone & 2 (mild) & Electrolyte imbalance \\
\hline 31 & G4P2L2A1 & $28+4$ & 36 & Preeclampsia & 2 (mild) & Electrolyte imbalance \\
\hline 37 & $\begin{array}{l}\text { G4P1L0A1 } \\
\text { prior cesarean }\end{array}$ & 19 & 35 & Idiopathic & 4 (severe) & Severe preeclampsia \\
\hline 19 & G1 & $15+6$ & 34 & Hypertriglyceridemia & 3 (severe) & Electrolyte imbalance \\
\hline
\end{tabular}

O.S- obstetric score; GAO - gestational age at onset; GAD - gestational age at delivery

The duration of stay in hospital was maximum for patients with biliary pancreatitis with a mean duration of 18.5 days and minimum for the patient in whom etiology couldn't be determined (4.5 days) as depicted in Figure 1.

During the study period of 5 years, 11053 women delivered and among them 6 mothers had acute pancreatitis and the total numbers of episodes were 14 . Incidence of acute pancreatitis in pregnancy was 1 in
1831 in our study. The demographic and clinical features of the cases are shown in Table 1. The age of patients ranged between 20 and 37 years with a mean of $26.6 \pm 6$. Two patients were nulliparous and 4 were multiparous. Two patients were in the second and 4 patients were in the third trimester at the time of presentation. The mean gestational age at onset was $27.16 \pm 6.7$ weeks and the mean gestational age at delivery was $34.42 \pm 2.6$ weeks. 
Patient with hypertriglyceridemia had maximum number of recurrences (4 episodes), following conservative management requiring hospital admission and patients with biliary pancreatitis and preeclampsia had the minimum ( 2 episodes) as shown in Figure 2.

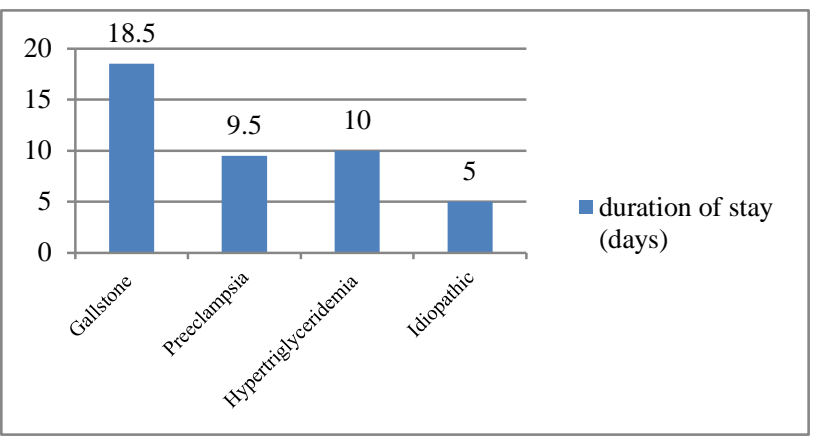

Figure 1: Relationship between length of hospital stay and etiology.

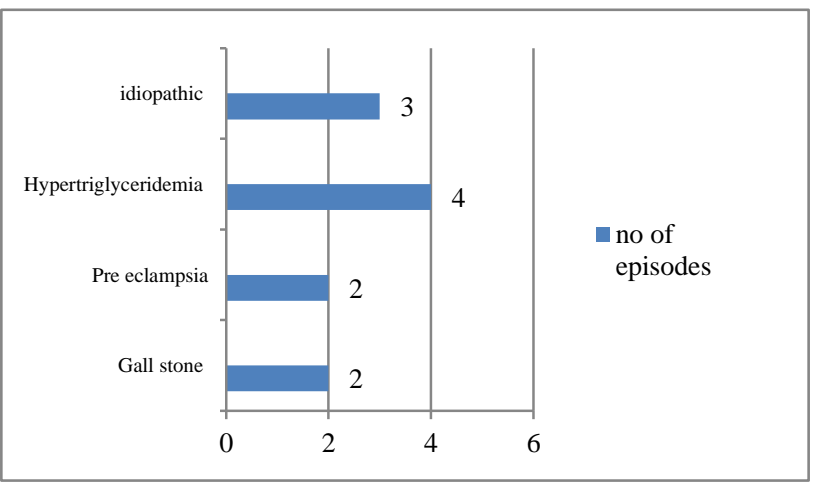

Figure 2: Association between number of episodes of acute pancreatitis and etiology.

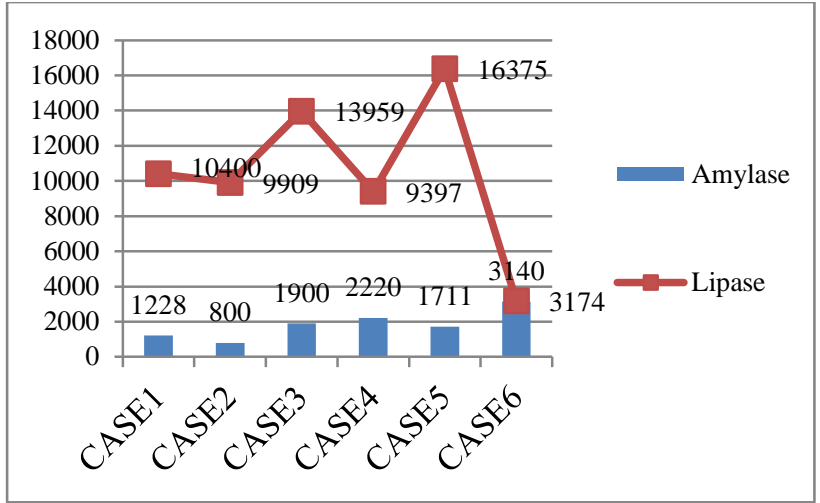

Lab cut-off: Normal serum amylase: 25 - 115 U/L, normal serum lipase: $73-393 \mathrm{U} / \mathrm{L}$

Figure 3: Levels of serum amylase and serum lipase in acute pancreatitis in pregnancy.

The cause of pancreatitis was biliary pancreatitis in 2, preeclampsia 2, hypertriglyceridemia in 1, idiopathic 1 . Ranson's score of $\leq 2$ were classified as mild pancreatitis $\geq 3$ as severe pancreatitis. Among the six, 3 cases were diagnosed with severe pancreatitis; the other 3 had mild pancreatitis. The serum amylase and serum lipase levels in the patients are depicted in Figure 3. Patients with acute pancreatitis of unknown cause had maximum serum lipase level $(16375 \mathrm{U} / \mathrm{L})$ and patients with hypertriglyceridemia had the minimum (3174 U/L). Serum amylase levels were maximum in patients with hypertriglyceridemia $(3140 \mathrm{U} / \mathrm{L})$ and minimum in patients with preeclampsia $(800 \mathrm{U} / \mathrm{L})$ and this association is depicted in Figure 3. The mode of delivery and perinatal outcome is depicted in Table 2 .

Table 2: Mode of delivery and perinatal outcome.

\begin{tabular}{|c|c|c|c|c|c|c|}
\hline Cases & $\begin{array}{l}\text { Mode of } \\
\text { delivery }\end{array}$ & $\begin{array}{l}\text { Apgar } \\
\text { (1 min) }\end{array}$ & $\begin{array}{l}\text { Apgar } \\
(5 \mathrm{~min})\end{array}$ & $\begin{array}{l}\text { Birth weight } \\
\text { (kg) }\end{array}$ & $\begin{array}{l}\text { NICU stay } \\
\text { (days) }\end{array}$ & Complications \\
\hline I & $\begin{array}{l}\text { Emergency } \\
\text { LSCS } \\
\text { (worsening of } \\
\text { maternal } \\
\text { condition) }\end{array}$ & 6 & 8 & 2.08 & 7 & Prematurity \\
\hline II & PTVD & 8 & 9 & 1.22 & 10 & Prematurity \\
\hline III & FTVD & 8 & 9 & 2.24 & & IUGR \\
\hline IV & PTVD & 7 & 8 & 1.8 & 7 & IUGR \\
\hline V & $\begin{array}{l}\text { Emergency } \\
\text { LSCS } \\
\text { (previous scar } \\
\text { dehiscence) }\end{array}$ & 5 & 7 & 2.7 & 3 & - \\
\hline VI & $\begin{array}{l}\text { Emergency } \\
\text { LSCS (fetal } \\
\text { distress) }\end{array}$ & 7 & 8 & 2.0 & 2 & - \\
\hline
\end{tabular}

Emergency LSCS - Emergency lower segment cesarean section; FTVD - Full term vaginal delivery; PTVD - Preterm vaginal delivery 
Preterm delivery occurred in 5 out of 6 patients; the cause of preterm delivery in our study was PROM (case 1), spontaneous preterm labor (case 2, 4 and 5), and fetal distress (case 6). Of the three patients with mild pancreatitis, one delivered beyond 37 weeks, and two patients delivered before 34 weeks. Three patients with severe pancreatitis delivered before 34 weeks. Three patients delivered vaginally and three patients had cesarean. The indications for cesarean were fetal distress (case 6), previous cesarean with scar tenderness (case 5) and worsening of maternal condition (case 1).

Two patients underwent ERCP (Endoscopic retrograde cholangiopancreatography) postpartum and all 6 patients were followed up till date with no recurrence.

\section{DISCUSSION}

The incidence of acute pancreatitis in pregnancy (APIP) was 1 in 1831 which correlates with other studies. Pancreatitis can occur during any trimester, but most commonly occurs in third trimester in more than $50 \%$ of the cases. ${ }^{11}$ In our study $66.67 \%$ of the patients presented in third trimester. The age of patients ranged between 20 and 37 years in our study. Previous studies showed that approximately one third of the women developing pancreatitis during pregnancy were nulliparous. In our study $33.33 \%$ (2/6) were nulliparous and $66.67 \%(4 / 6)$ were multiparous which again correlates with previous studies. ${ }^{12}$ In non-pregnant patients, biliary disease and alcohol abuse are the most common causes whereas other reasons such as mechanical, metabolic, vascular or infectious factors also may be found. In pregnancyassociated pancreatitis gallstones are the most frequent cause which is supported by most studies with an incidence ranging from $57 \%$ to $100 \% .{ }^{13}$ In our study the most common etiological factor was shared by gallstones and preeclampsia $(33.33 \%$ each) and idiopathic and hypertriglyceridemia ( $16.67 \%$ each).

Patients with biliary pancreatitis had the maximum duration of hospital stay with a mean duration of 18.5 days and minimum for patients for whom etiology couldn't be determined (4.5 days). In our study, the numbers of recurrences of acute pancreatitis episodes were maximum with hypertriglyceridemia (4 episodes) during the duration of observation that is from the onset of first episode till delivery, followed by idiopathic pancreatitis with 3 episodes and biliary pancreatitis and preeclampsia had the minimum of 2 episodes. In our study, relapse rate of biliary pancreatitis accounted for $45 \%$ of cases, while in other studies according to Swisher et al and Dixon et al, relapse rate was $70 \% .^{14,18}$

No surgical intervention was required in our study. Despite initial concerns pregnancy is not a contraindication for laparoscopic surgery and it is associated with good maternal and perinatal outcome. ${ }^{15,16}$ Ranson's score was used to grade the severity of pancreatitis and were graded as mild pancreatitis when score was $\leq 2$ and as severe pancreatitis when $\geq 3$. In our study $50 \%$ had severe pancreatitis, another $50 \%$ had mild pancreatitis but according to Aytul et al $42 \%$ had severe pancreatitis. $^{12}$

On evaluating the relationship between the etiology and laboratory values of serum amylase and serum lipase levels in the patients, pancreatitis secondary to idiopathic etiology had maximum serum lipase level (16375 U/L) and patient with hypertriglyceridemia had the minimum (3174 U/L). Serum amylase levels were maximum in patient with hypertriglyceridemia $(3140 \mathrm{U} / \mathrm{L})$ and minimum in patient with preeclampsia (800 U/L). All patients were managed conservatively during the episodes and all attempts were made to prolong the gestation in order to improve the perinatal outcome.

The most common complication encountered during these episodes was electrolyte imbalance (66.66\%), followed by ARDS (33.33\%). Two patients were managed in intensive care unit (ICU) (case 1 and 2), indications being ARDS and electrolyte imbalance. While case 1 was shifted to ICU for ARDS on the first postnatal day, case 2 had preeclampsia at 30 weeks and developed ARDS and shifted to ICU. Both were managed conservatively and improved. There was no maternal mortality in our study.

Three patients underwent emergency lower segment cesarean section for obstetric indications and 3 had vaginal delivery of which two were preterm and one delivered at term. Five out of six patients had preterm delivery $(83.33 \%)$ and all 6 babies had birth weight $<2.5$ $\mathrm{kg}$. The mean birth weight was $2.008 \pm 0.490 \mathrm{~kg}$. Four babies required NICU stay with longest duration being 10 days and least being 2 days. There was no neonatal mortality. The marked reduction in perinatal mortality described in more recent series reveal improvements in neonatal intensive care. ${ }^{17,18}$

All 6 patients were followed up for 1 year postnatally, of which 2 underwent ERCP and didn't have any recurrences. Hence, despite the etiology of origin acute pancreatitis can be managed conservatively during pregnancy to prolong the gestation.

\section{CONCLUSION}

Expectant management with multidisciplinary team has improved maternal and perinatal outcome. Recent advances in diagnosis and treatment have substantially improved our understanding of this dynamic organ and its systemic effects. Treatment to avoid potential sequelae has reduced maternal and perinatal death.

Funding: No funding sources Conflict of interest: None declared

Ethical approval: The study was approved by the Institutional Ethics Committee 


\section{REFERENCES}

1. Whitten AE, Lorenz RP, Smith JM. Hyperlipidemiaassociated pancreatitis in pregnancy managed with fenofibrate. Am J Obstet Gynecol. 2011;117:517-9.

2. Papadakis EP, Sagianni M, Mikhailidis DP, Mamopoulos A. Acute pancreatitis in pregnancy: an overview. European J Obstet Gynecol Reprod Biol. 2011;159:261-6.

3. Hua-ping L, Ya-jaun H, Xuan C. Acute pancreatitis in pregnancy: a 6-year single center clinical experience. Chin Med J. 2011;14:2771-5.

4. Choy CMY, Tam WH, Leung TN. Gestational hyperlipidemic pancreatitis. BJOG. 2002;109:847-8.

5. Badja N, Troche G, Zazzo JF, Benhamou D. Acute pancreatitis and preeclampsia-eclampsia: a case report. Am J Obstet Gynecol. 1997;176:707-9.

6. Opatrny L, Michon N, Ray E. Preeclampsia as a cause of pancreatitis: a case report. J Obstet Gynaecol Can. 2004;26:594-5.

7. Parmar MS. Pancreatic necrosis associated with preeclampsia-eclampsia. JOP. 2004;5:101-4.

8. Crisan LS, Steidl ET, Rivera-Alsina ME. Acute hyperlipidemic pancreatitis in pregnancy. Am J Obstet Gynecol. 2008;198:57-9.

9. Al-Haddad M, Wallace MB. Diagnostic approach to patients with acute idiopathic and recurrent pancreatitis, what should be done? World J Gastroenterol. 2008;14:1007-10.

10. Ranson JH, Rifkind KM, Roses DF, Fink SD, Eng K, Spencer FC. Prognostic signs and the role of operative management in acute pancreatitis. Surg Gynecol Obstet. 1974;139:69-81.

11. Nanda S, Gupta A, Dora A, Gupta A. Acute pancreatitis: a rare cause of acute abdomen in pregnancy. Arch Gynecol Obstet. 2009;279:577-8.

12. Aytul. Maternal and perinatal outcomes of acute pancreatitis during pregnancy. Gaji Medical Journal. 2012:133-137.

13. Hernandez A, Petrow MS, Brooks DC, Banks PA, Ashley SW, Tavakkolizadeh A. Acute pancreatitis and pregnancy: A 10-year single center experience. J Gastrointest Surg. 2007;11:1623-7.

14. Dixon NP, Faddis DM, Silberman H. Aggressive management of cholecystitis during pregnancy. Am J Surg. 1987;154:292-4.

15. Gurbuz AT, Peetz ME. The acute abdomen in the pregnant patient. Is there a role for laparoscopy? Surg Endosc. 1997;11:98-102.

16. Cohen-Kerem R, Railton C, Oren D, Lishner M, Koren G. Pregnancy outcome following nonobstetric surgical intervention. Am J Surg. 2005;190:467-73.

17. Ramin KD, Ramsey PS. Disease of the gallbladder and pancreas in pregnancy. Obstet Gynecol Clin North Am. 2001;28:571-80.

18. Swisher SG, Hunt KK, Schmit PJ, Hiyama DT, Bennion RS, Thompson JE. Management of pancreatitis complicating pregnancy. Am Surg. 1994;60:759-62.

Cite this article as: Vishnu Priya KMN, Sheela CN, Banka S, Mahalakshmi T. Maternal and perinatal outcome of acute pancreatitis during pregnancy: a 5 year experience at a tertiary care centre. Int J Reprod Contracept Obstet Gynecol 2016;5:4041-5. 